\title{
The Ambiguity Surrounding Parents' Role on Sex Education Of Their Children: Nigeria Experience
}

\author{
Dr. (Mrs.) Esther Uko, Ayuk, Awunghe Achu \\ Dept. of Education Planning \& Admin. University of Calabar. \\ Department of Sociology University of Calabar.
}

\begin{abstract}
Concern about parent's ineptitude and general amnesia of the danger of not discussing sexually related topics with their adolescent children is not only selfish but also criminal and irresponsible. This work is an attempt and a wakeup call to parents and teachers as well as the Nigerian government to be more involved and see that sexuality education occupies a central stage in the school curriculum. Hence, this work examines issues on parental obligation in sex education, age and time; school/teachers and sexuality education. Methodologically, the survey design was used and independent t-test served as the statistical tool for the analysis. The findings reveal that most parents do not, and are not comfortable in discussing sexual health and safety with their children. The study made some recommendations among which include the need for parents to ask questions, bordering on their children's sexuality with love, friendly concern and not being intimidating.Equally,policy makers should introduce bills to make sex education mandatory in the school curriculum at least from post primary schools.
\end{abstract}

\section{Introduction}

In recent times, the rapid rise in sex and sexually related activities among adolescents in Nigeria is quite disturbing and worrisome as lewd expressions and actions within this class seem normal, and even heralded, and often times are seen as "fashionable" (Ayuk, 2012). This according to Onete,Eyo \&Ude (2009), is because of a disconnect from the home environment, which understandably suppose to be where a child starts to socialize and to be socialized.

No doubt in the past 30 to 40 years in Nigeria adolescent sexually related activities have increased tremendously and reports have it that, male adolescents have had sexual experience by age(s) 18 and females at age(s) 12 to 13, respectively (Cattel, 2004). This state of affairs is not unconnected with lack of parents' attitude towards sexuality education. As it is, parents are expected to equip and expose their children to varied sources of knowledge related to their sexuality. Unfortunately, as observed by Onete et al (2009), the practice of parent's attitudes and sexuality education is grossly bereft in Nigeria. Even parents with requisite exposure and knowledge feel uncomfortable talking to their children at home about the subject, which incidentally is indispensable to the adolescents' sexual life and parents' happiness (Ayuk, 2012).

Preponderance of African culture abhors discussion bordering on sex publicly, rather sex related issues are considered sacred or sacrosanct and not to be discussed in the presence or hearing of the children. This attitude rather than helping, arouses inquisition in the minds of teenagers to seeking information from uncontrolled and not well informed sources like peer groups, films, magazines etc which in truth pose dire consequences.

During this period of information technology, it would be a mistake for parents to take for granted sex education of their children. Normally, children who are not knowledgeable about their sexual safety display ignorance of their reproductive physiology, sexually transmitted diseases (STDs), and sexual circles (for females), when they are safe and other risk factors not mentioned, associated with sexuality. It becomes even more devastating as some end up so early in "THE - FAMILY - WAY" i.e. pregnancy and for the males becoming fathers -unexpectedly) (Joseph, 2007, Barker and Rich 2002 and Onete, 2009).

This phenomenon of not discussing sexuality imperatives is not restricted to only the uneducated Nigerians. Even the educated parents do not guide or counsel their children for fear that the children would experiment with sex, but apparently ignorant of the fact that sex is a natural instinct and parents owe the children the responsibility and onus to teach them to learn about sex in dignified ways (Joseph, 2007).

It is the realization of the inherent dangers for adolescents not to be taught, counseled and properly informed about their sexuality that has necessitated the establishment of NGO's like Girls Power Initiative, Women's Health and Empowerment and other related health schemes/programmes geared towards providing accurate information with increased knowledge of adolescent sexuality. This according to Madunagu (2007), would assist adolescents especially the girls to claim and reclaim their courage, develop high self - esteem and take actions from informed position to reduce risk to their lives. 
Albeit, awareness campaigns carried out by Ministry of Health in Nigeria at all levels of government (local, state and federal) via radio, television, newspapers etc, seem not to have galvanized parents to adequately address the need of sexuality education with their adolescent children. There are prevalent cases of unprotected sexual activity, resulting in unwanted pregnancy, abortion complications, taking unprescribed contraceptives, high incidence of sexually transmitted diseases (STDs) and HIV/AIDS.

This impliedly suggests that, sexuality education is still lacking especially from our homes (parents) which normally play the functional role in the development of the children. This study is therefore a response to investigate the ambiguity surrounding parents' role on sex education of their children. Objectively, the study assesses and examines the role of parents in partnership with the school/teachers as sex health educators of their children/wards. Hence the questions:

a) In what ways do or can parents educate their children about sex and relationship?

b) Do parents really need some skills to perform this task of educating their wards about sexuality?

c) To what extent can parents collaborate with schools vis-a-vis teachers to educate adolescents in sexuality?

\section{HYPOTHESIS}

To guide this study the following hypothesis was formulated:

$\mathrm{H}_{0}$ : $\quad$ Parents do not need any skill and partnership with schools vis-à-vis teachers in sexuality education of their children.

\section{SEXUALITY EDUCATION (OVERVIEW)}

There have been so much controversies particularly with regard to the age of which children should start receiving sex education. The amount of details over the years in Nigeria has shrouded sexuality education in respect to adolescents with regards to several groups, scholars, religious leaders, women activists, to mention but just a few; as to whether educating adolescents about their sexuality would impact negatively or positively on their values and moral dispositions.

These differences in opinion do not rationally stop us to ask whether sexuality education is useful to the general health of the adolescents and by extension the society. If the answer is in the affirmative, what then is sex education?.In a broad term ,sex education is used to describe knowledge and information about human sexual anatomy, sexual reproduction and sexual intercourse (anser.com Retrieved, 15/9/2013).It Is also any instruction in the process and consequence of sexual activity, ordinarily given to children by parents at home or teachers in classroom lessons about sex, taught in primary and secondary schools to include sexually related aspects of human life, physical and physiological development, behaviours, attitudes and social customs associated with the individual's sense of gender, relationships, sexual activities, mate selection and reproduction (Coon, 2006).

Sexuality education is also the systematic attempt to promote healthy awareness in an individual on matters of his or her sexual development, functioning, vigor and attitudes through direct teachings. It involves issues on safe sex practices, the use of birth controls, such as condom and oral contraceptive and the impact of such use on pregnancy outside marriage, teenage pregnancy etc. It deals with emotional relations, reproductive rights and responsibilities - abstinence and birth control, common avenues for parents or caregivers, to teach or be taught via formal schools and public health campaigns (Barbara, 2013 and Ayuk, 2012).

Sexuality education could be summed up as empowering adolescents generally to negotiate in relationship to reduce early and unplanned parenthood, reducing risky sexual behaviours, building confidence, encouragement by creating awareness to one about harmful practices and the significance to make or take decision from informed position. It explains the acquisition of knowledge that deals with human sexuality and consists of instruments in the development of an understanding of the physical, mental, environmental, social, economic and psychological phases of human relations as they affect male and female existence or coexistence.

Sex education is all about teaching of human values, ethical principles and concepts in relation to male and female which connote a mechanism or procedure which stands for the protection, improvement and development of the family based on acceptable ethical ideals. Consequently, it provides a sound knowledge of human reproduction, a check on misuse and abuse of sex, information on sexually transmitted diseases, a check on activities of commercial sex workers, prevention and control of immodesty, information on preparation for family life and marriage (Onete, 2009).

\section{Methods And Parental Obligations On Sex Education}

Parents' disposition in promoting the sexual health and rights of their wards to aspire and achieve higher educational and professional status as well as mobilize them for overall development is very needful. This is done by training that involves documenting and assessing the understanding and knowledge of the 
children on health issues (sexuality), human rights, personal empowerment etc, that would assist them identify what to do right in respect to sexual concerns and not (Ayuk, 2012 and Madunagu, 2006).

Leon (1973), opined that conducting educational sessions on personal hygiene and counseling adolescents on sexual health related issues should form part of the parents duties to their children, because adolescents face serious educational and health problems and these include; according to Madunagu (2006);

a) Early sexual initiation and unsafe sexual practices.

b) Unwanted pregnancies (unpreparedness by both male and female).

c) Unsafe abortion resulting in high mortality rates among adolescents( girls).

d) Sexually transmitted infections, including HIV/AIDS.

e) Early marriage.

Parents ought to be primary sex educators of their children and should be the ones to communicate to them specific values about sexuality because it is the parents' right and responsibility. Parents should not wait for the children to ask questions about sexuality, rather they should initiate the conversation. As a parent, be always alert to "teachable moments" and seize the opportunity. They should use everyday situations and occurrences like watching films to begin conversation about sexuality and to the point; go beyond the obvious, but with caution and stop when it is necessary (Madunagu 2006). Ekpeha (2013), stressed that attitude of parents towards sexuality education of adolescents occupies an important place in understanding their reaction to sexuality. This will help parents to uncover those determinants that shape their opinion or reaction to reproductive health of adolescents who are victims of careless sexual activities.

Joseph (2007), notes that there exists certain influences that shape attitude of parents towards sexuality education of adolescents (unwillingness and reticence ) in Nigerian society. It is important that "the - hold back" parental attitude in this domain be modified. Adolescents deprived of sex education by parents run the risk of carrying abortion with home remedies, patent medicine or pay visits to private health care providers, like traditional healers and quack physicians, which of course is counterproductive. Arguably, there are certain universal procedures in orienting adolescents towards sexual and reproductive health knowledge; although program practices for adolescents and reproductive health varies from one country to another and cultures, respectively. Notwithstanding the variations in practice and procedures, it is important to encourage and create awareness to adolescents expressed in providing information about reproductive system, how pregnancy can occur, proper use of contraceptives etc.

It should be noted that change during adolescent years are inevitable and that parents should learn to examine expected behaviour and handle feelings associated with these changes (Bene, 2006). Sexuality is a natural and positive aspect of being human, therefore parents should freely discuss sexuality intrigues with their wards using real life applications, be sincere and be sure the meaning of new words are clear and understood. Communication with children on sexuality should be both verbally and non - verbally because children are aware of what you do and don't (Opcit, 2006).

Parents should not shift responsibilities to teachers or the educational system because parents are seen as most effective sexuality educators, even though the role is discomforting. Bene (2006), concludes that if your children ask questions, do not worry about whether they are too young to know the answers, since children understand what they are ready to understand. However,give answer at your child's level of understanding and ask for feedback to determine what he or she has understood; and remember, every question is an opportunity to discuss values, information and feelings and listen attentively to them, let them know that you care about their feelings and respect their ideas even if you do not agree with them.

\section{SEXUALITY, AGE AND TIME FOR COMMUNICATION}

There is general agreement among experts in child rearing that sex education should start early and be dealt with in an open and natural way (Mac, 2008). Understanding parental decision about when to talk with teenagers shows that, most parents do not even bring the topic and prefer it discussed when their children are about to marry, which is risky because often times, at this stage a lot of damages have already been done and could lead to fixation, trauma and other negative health implications. Adolescents whose parents discuss sexual health and safe sex with, early enough seem to engage in less risky sexual behaviour than those whose parents do not (Holtzman and Pubirison, 2005). Equally it has been proven that adolescents whose parents had communicated with about sex were more likely to delay sex than their peers whose parents had not communicated.

There is no doubt that family approaches to sexuality education influence children's sexual orientation. Children or adolescents have mix ideas about their parents - and feel that, parents might seem too rigid about sex and this makes them rebellious and retire to self experiment (Haffner, 2005). No time is right and wrong in sex education and parents should not use this to absolve themselves of the responsibility to translate their own feelings about sexuality into messages for their children. Human sexuality has long been surrounded by guilt, mystery and controversy, and that many parents feel unprepared and embarrassed to talk to their children about 
matters concerning sex. As a result, there is the likelihood for miscommunication and misperception between parents and adolescents about sex (Moore and Rosenthal, 2006).

Families where communication is easy and where warmth and affection are exhibited are more likely to have positive talk about sexuality. It should be noted that in sexuality discussion, children tend to choose between the parents who they can freely discuss with. For example Ballard, Peterson and Morris (1998), found out that young males prefer confiding in the mothers, while females confide more in friends with little trust in their mothers and fathers on sex related issues.

Nolin (2003), reported that only half of the boys had engaged in a conversion with their parents about sex and social issues relating to sexuality or contraception. The report held that majority of parents had never had meaningful discussion with their wards about sex, safe sex, sex before marriage or peer pressure (Lorusso, et al, 2008). What parents constantly discuss is book knowledge, information from educational videos and books about reproduction and sexuality.

To support this claim Epstein and Ward (2007), conducted a study on sexuality education seeking to understand adolescent's communication with their parents. It was revealed that almost 300 university students who were asked retrospectively what their parents have told them about sex, nearly a quarter answered "nothing". Infact,these adolescents felt that their parents avoided the topic. While some parents blamed their actions on inadequate sex education which they had received themselves as adolescents and were angry that they could not overcome what they said as their limitations with their children.

\section{CHOOL/ TEACHERS AND SEXUALITY EDUCATION}

School and teachers, no doubt have a major role(s) in impacting sex education knowledge to adolescents, because it is only an individual from informed background that can best protect and stand for his or her right (Ayuk, 2012 \& Bene 2006).Teachers are seen as instructors, mobilizers, enablers, helpers and transmitters of knowledge from generation to generation via the school system. Teachers through formal school setting create sufficient awareness, socialize and resocialize adolescents on a variety of issues, and should not be left out as sex educators agents of children (Ayuk, 2012).

Teachers should create time during studies to share knowledge about sexual health of children and facilitate dialogues, that would make the children ask questions. Children believe and respect their teachers and with this understanding, teachers are expected to objectively offer themselves to truth and realistic knowledge devoid of religious and cultural fallacies on sexuality. For example, some teachers who are religiously chained might wrongly impact on the children. Take for instance, the issue of virginity, some may consider a non- virgin an infidel caused by promiscuity but not knowing that through other means, like sports, one can be disvirgined.

Teachers/schools through a well crafted syllabus should provide sufficient knowledge on sex education for teenagers, as they are at the core of the discussion, as this will facilitate their understanding about sex and what risk might come from it. Teachers should not make sex subject a taboo, immoral or false belief. Rather, they should fully discuss it, as a mandate of giving students needed information for life that will extricate them from sex related harms. It is time to prepare teachers with sufficient knowledge and training for sex education, qualified counseling teachers, who not only have sufficient knowledge and psychological instruments, but also universal values that can dialogue on daily students affairs, facilitated in classroom with open and informed approach to sex education, which is more moral and rewarding.

Teachers should assist adolescents to take action to overcome the risk to their sexual health, build leadership skills and take active engagement in issues of sexuality by sensitizing them on risky behaviours harmful to their health. They should give information that will help them to struggle against harmful traditional practices and claim their rights as human beings. Giving of information by teachers through participatory learning approach to impart life management skills helps them overcome stereotypes (Bene, 2006).

\section{Theoretical Consideration}

Theories give impetus to social phenomena explicability. This work would adopt the social learning theory to explain and analyse the concept of parents role on sex education of their children.

\section{Social Learning Theory:}

This theory was proponented by Albert Bandura and Robert Sear. The theory assumes that people learn in the social context- and are facilitated through observation and modeling. It holds that a model is an important source for learning new behaviour and for achieving behavioural changes in an institutionalized setting like the family. Social learning theorists argue that learning can occur in relation to three dimensional models, viz; Life model,verbal instruction and symbolic.Life model takes place when an actual person is demonstrating the desired behaviour. Verbal instruction, which is the second, supposes an individual behaviour in details, describing how one engages in a desired action behaviourally. Symbolic involves modeling that occurs in 
media, movies, internet, literature and radio. The theory further assumes that, people especially children learn from the environment and seek acceptance from society by learning through influential and experiential models.

\section{IMPLICATION}

The implication is that parents should teach their adolescent children sex education and guide them not to engage in risky sexual behaviour by constantly discussing and communicating the true position of sex with them - this is necessary because children tend to listen and imitate their significant others (parents and teachers). Through instructions, parents and teachers can inculcate the right knowledge on sexuality awareness. Failure to teach them, results in the risk of learning negative sexuality behaviours from the mass media, peer groups, internet to mention but a few.

\section{Methodology}

The design method adopted for this study is the survey design, which studies both small and large population by selecting and studying samples chosen from the population to discover the relative incidence distribution and interrelation of different variables. In addition, the study design explains the purpose and basis of the plan of action that was followed throughout the conduct of the research. This design method is apt because it allows for easy collection of data, tabulation and analysis as well as generalization of findings.

The sample size of 20 students from the 36 States of the Federation totaling 720 through purposive sample technique served as a workable sample and the research instrument used for data collection from the subject is a set of 25 items questionnaire. The research adopted independent t-test instrument for the analysis.

\section{THE HYPOTHESIS}

Parents do not need skills and partnership with schools vis-à-vis teachers in sexuality education of their adolescents' children.

Dependent Variable (Y): Parents Skills.

Independent Variable (X): Adolescents Sexuality.

Statistical Analytical Procedure = Population t- test analytical procedure of one sample mean shall be adopted in determining the extent to which parental skills can impact sexuality education of adolescents.

Table 1:

Independent $\mathbf{t}$ - test analysis of parental skills and sexuality education of adolescent $(\mathbf{N}=720)$.

\begin{tabular}{cccccc}
\hline $\mathbf{N}$ & $\mathbf{X}$ & $\mathbf{S D}$ & $\mathbf{D f}$ & $\mathbf{t}$-cal & Sign \\
\hline 350 & 74.47 & 4.15 & 8.68 & & \\
370 & 74.74 & 4.15 & 40 & $0.127^{*}$ & .132 \\
720 & 74.61 & 6.42 & & & \\
\hline
\end{tabular}

Not significant at $\mathrm{P}<.05, \mathrm{df}=40$ crit $-\mathrm{t}=1.968$

From the Table, the calculated t-value of $1.132 *$ was found to be far higher than the critical t-value of 1.968 needed for significance at 0.05 alpha level with 40 degrees of freedom. With this, the hypothesis is rejected, implying that there is a significant relationship between parents' skills and adolescent' sexuality.

\section{Discussion}

The analysis of the hypothesis revealed that parents' skills are significant and imperative to sexuality education of adolescents in Nigeria. Findings showed that a few young people whose parents discuss sexual health and safe sex with them were found to have delayed in engaging in sex and expressed appreciation to their parents. However, those whose parents hoard sex education discussion, subsequently learn from their peers, newspapers, internet etc, and became victims of early pregnancies vis-à-vis young and unprepared fathers This development subsequently stalled their aspirations educationally, economically and socially.

Equally noted via the findings, teachers were seen as powerful instruments in passing pieces of information about sex education to adolescents. The belief is that, children see teachers as infallible, uncontradictory, honest and knowledgeable in almost every "subject area". With this understanding, it was only natural that teachers used this privilege position to educate the adolescents about their sexual health. Finally, it was revealed that Nigerian parents, no matter their level of education or exposure would seek to strike a balance between being intrusive with their adolescent children and avoid sex related topics altogether which confirms Haffner (2005), assertion that parents fail and are always reticent in discussing sex related issues; rather sex discussions are more or less conveyed with warnings and threats.

\section{Conclusion}

The main thrust of this study was to examine the ambiguity that surrounds parents general behaviour on sexuality education of adolescents in Nigeria. Hence, it was hypothesized that: parents do not need any skills and the partnership of schools vis - a- vis teachers in sexuality education of their adolescent children. The 
survey design was adopted and independent t-test used as the statistical instrument. The outcome of the study shows that: parents have significant role(s) to and in educating their children on sexuality. Equally, schools as concerns teachers can teach and sensitize adolescents about their sexuality.

\section{RECOMMENDATIONS}

Based on the findings of the study, the following recommendations were made;

1) Parents should not shy away from discussing issues of sexuality with their children.

2) Parents should ask questions bordering on their children's sexuality but with care and love not harshful and intimidating.

3) Policy makers and Legislatures should enact bills that will make sex education mandatory and taught in all schools.

4) Teachers should objectively pass on knowledge to children about sex education devoid of any religious or cultural coloration and harassment to the children.

5) Seminars, workshops and conferences should be organized from time to time to keep adolescents abreast about their sexuality.

\section{References}

[1]. Ayuk, A. (2012). "Violent crime Against A Girl Child. A Paper Presented at Etung Student" Forum. Unpublished.

[2]. Bene, M. (2006). Women's Health and Empowerment, Speeches, Essays and Lectures. Clear Lines Publications - Calabar Nigeria.

[3]. Barbara, H. (2013). Sex Education. Wikipedia.org. Retrieved 17/9/2013.

[4]. Ekpeha, F. (2012). Parental Attitude and Sexuality Education of Adolescents: A Case Study of Calabar South - Nigeria. B.Sc. Thesis submitted to Department of Sociology, University of Calabar.

[5]. Cattel, L. (2006). Sexual Behaviour of Young Adults in Latin America. Psychosocial Perspectives Vol.2, 231 - 252.

[6]. Coon, (2006). Sexuality Education of Young Children. Parent Concern and Family Relations Journal Vol.41 pp. 142-143.

[7]. Epstein, M. and Ward, L. (2007). Always Use Protection, Communication Boys Receive About Sex From Parents, Peers and The Media. The journal of youth and adolescence Vol.37.

[8]. Eyo, M. (2009). Parental Attitude and Sexuality Education of Adolescent in Central Cross River State. Nigeria Journal of Social and Development Issues Vol.6.

[9]. Haffner, K. (2005). Children Engage in Sexual Behaviour Through Attitude. Journal of Sex Research Vol.42.

[10]. Haltzman and Pubirison (2005). Adolescents engage in risky sexual behaviour. Journal of sexual behaviour Vol.12.

[11]. Joseph, E. (1997). A Study of The Reproductive Health of The Adolescent. Unpublished M.Sc Thesis, submitted to Graduate School - University of Calabar.

[12]. Lehr, D., Delorio, C. and Facteau (2005). Predictions to Father - Son "Communication About Sexuality. The Journal of Sex research Vol. 42.

[13]. Nolin, M. \& Petterson, K. (1992). Gender Differences in Parent Child Communication About Sexuality - An Exploratory Study. Journal of adolescent research. Vol.7.

[14]. Onete, O. Ategwu, Eyo, M. \& Udey, F. (2009). Parental Attitude and Sexuality Education of Adolescents in Central Cross River State. Nigerian Journal of Social and Development Issues. Vol.6.

[15]. Rosenthal, D. (2002). Fathers Difficulties in Communicating Sexuality with Adolescent. A New Direction for Adolescent Development journal Vol.97. 